\title{
Uniform Deformation Design of Outrigger Braced Skyscrapers: A Simplified Method for the Preliminary Design Stage
}

\author{
Arsalan Alavi ${ }^{1}$, Elena Mele ${ }^{2}$, Reza Rahgozar ${ }^{1}$, Ehsan Noroozinejad Farsangi ${ }^{3 *}$, Izuru Takewaki ${ }^{4}$ \\ \& Christian Málaga-Chuquitaype ${ }^{5}$ \\ ${ }^{1}$ Department of Civil Engineering, Faculty of Engineering, Shahid Bahonar University of Kerman, Kerman, Iran \\ ${ }^{2}$ Department of Structures for Engineering and Architecture, University of Naples Federico II, Naples, Italy \\ ${ }^{3}$ Faculty of Civil and Surveying Engineering, Graduate University of Advanced Technology, Kerman, Iran \\ ${ }^{4}$ Department of Architecture and Architectural Engineering, Kyoto University, Japan \\ ${ }^{5}$ Department of Civil and Environmental Engineering, Imperial College London, London, UK
}

Cite as: Alavi, A., Mele, E., Rahgozar, R., Farsangi, E.N., Takewaki, I. and Málaga-Chuquitaype, C., 2021, June. Uniform deformation design of outrigger braced skyscrapers: A simplified method for the preliminary design stage. In Structures (Vol. 31, pp. 395-405). https://doi.org/10.1016/j.istruc.2021.01.099

\begin{abstract}
A stiffness-based method for the preliminary design of outrigger braced skyscrapers is proposed. The method is founded on the concept of uniform distribution of deformation. This approach originates from the minimum-compliance optimization, in which the stiffest layout for the structure is sought for a given amount of material. Design variables include: the flexural stiffness of the core structure, the outrigger-belt elevation, and peripheral column dimensions. These parameters are specified by requiring the curvature to be kept constant, yet minimum, as long as the allowable stress and displacement constraints are imposed. The resulting procedure is presented through a simplified hand-calculation algorithmic framework, which may be used during the preliminary design stage to estimate the size of elements and to give an initial assessment of the structural behavior. In order to show the practical application of the proposed method, a structure equipped with one outrigger is designed using the proposed algorithm. The comparative analysis of the results reveals that the presented method provides a rather high degree of accuracy in practice.
\end{abstract}

Keywords: Tall buildings; Outrigger; Optimum strength and stiffness distribution; Performance-based design; Uniform deformation; Minimum compliance 
* Corresponding author: noroozinejad@kgut.ac.ir

\section{Introduction}

A major concern in the design of slender building structures, such as modern skyscrapers, is its behavior under lateral loads ${ }^{[1,2]}$, and in particular, its slenderness which can be quantified by its aspect ratio, i.e. the ratio of height to the footprint depth of the lateral structural system. Lateral deformation in structures must be severely controlled so that inhabitants feel comfort and to prevent any damage to the second-grade structural elements. ${ }^{[3]}$ Building deflections imposed by wind loads increase as a function of the building height and can be reduced by increasing the structural depth. Taking the vertical cantilever beam under uniform transversal load as a simplified model of the building behavior under wind loading, the above considerations can be easily grasped. A slender beam, characterized by an aspect ratio H/B (ratio of beam length to cross-section depth) equal to or larger than, say 10, behaves predominantly in flexure. ${ }^{[4]}$ Transverse loads acting on the cantilever cause internal actions, namely shear forces and overturning moments. Increasing the beam length (i.e. the building height), while increasing the resultant shear force linearly, causes the overturning moment to increase as a quadratic function of the length. Furthermore, the lateral deflections (i.e. the building drift) increase even more quickly, with the fourth power of the length. Quite trivially, one way of increasing the flexural stiffness of the beam is to increase the moment of inertia of its cross-section, which requires the distribution of the areas further away from the section centroid. For a building, the moment of inertia is calculated considering each of the vertical elements that are continuous along elevation and active in the lateral system, such as core walls and columns. Therefore, increasing the building stiffness requires the placement of such vertical elements as far as possible from the plan centroid, i.e. at the building perimeter. ${ }^{[5]}$ 


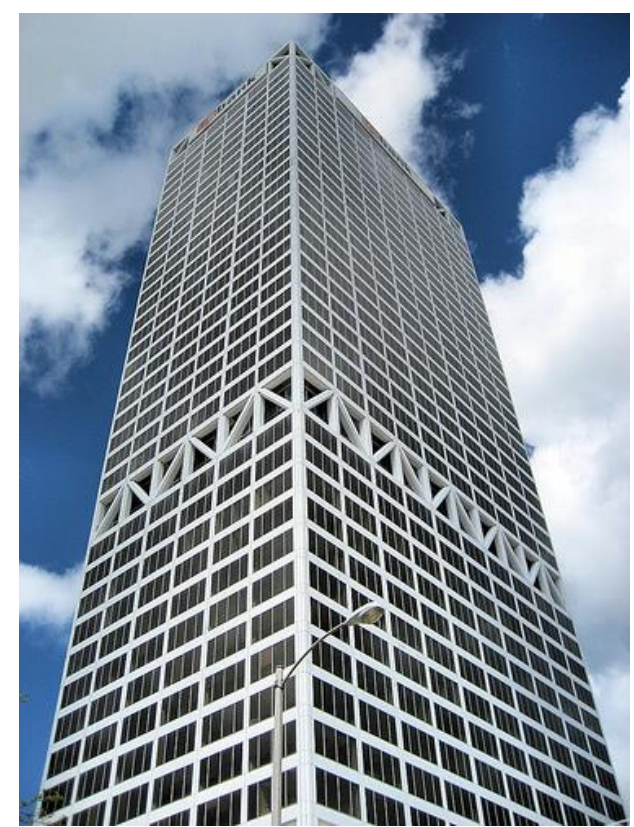

Fig. 1 US Bank Center building, equipped with a combined system of outriggers, core and belt trusses ${ }^{[6]}$

On the basis of this simplification, it is clear that counteracting flexibility is the most challenging problem in the design of tall buildings. The awareness of this fact has given rise to innovative and efficient structural systems. In this process, two major milestones can be identified: the concept of tube, according to which the vertical columns and bracings are moved to the perimeter to maximize the moment of inertia; and the system made of a core plus one or more outriggers, Fig. 1, which, though preserves the central location for the core structure, maximizes the lever arm of the equivalent beam cross-section by inserting a very stiff interconnection (outrigger) between the core and perimeter columns. The first applications of both systems date back to the 1960s. However, they are widely utilized today in different varieties and also as part of hybrid structural systems. ${ }^{[7]}$

An outrigger braced structure is highly efficient for high-rise buildings. This system consists of a steel-framed or reinforced-concrete-walled core connected to perimeter columns by flexurally stiff outriggers, Fig. 2. Belt trusses are provided to link exterior columns to each other. 


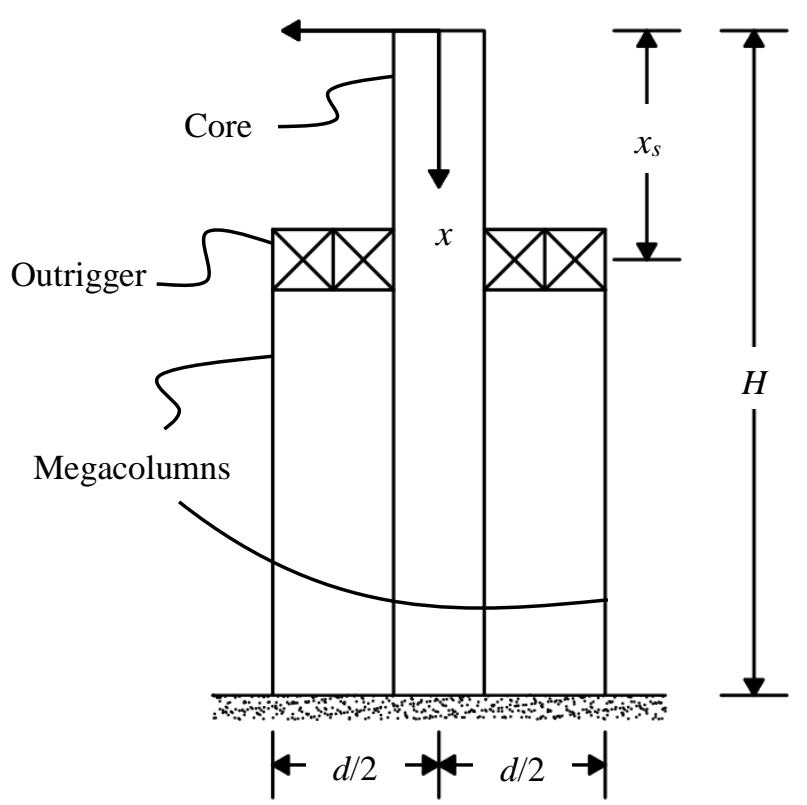

Fig. 2 Outrigger braced structure (updated from Ref. [8])

When the building is laterally loaded, a reversal moment is generated through a tension-compression action of the perimeter columns and transferred to the core structure via the outriggers, Fig. 3. Consequently, the bending moment in the core as well as the lateral displacements are considerably reduced, as compared to freestanding core counterparts. The effect of an outrigger connecting distant columns can be simply modeled as a twisting spring located at the outrigger truss elevation. When laterally loaded, the external forces are resisted not only by the core but also by this added spring. As a consequence, in addition to the lateral stiffness of the core, the spring properties, including its location and rotational stiffness, affect the global performance of the structure.

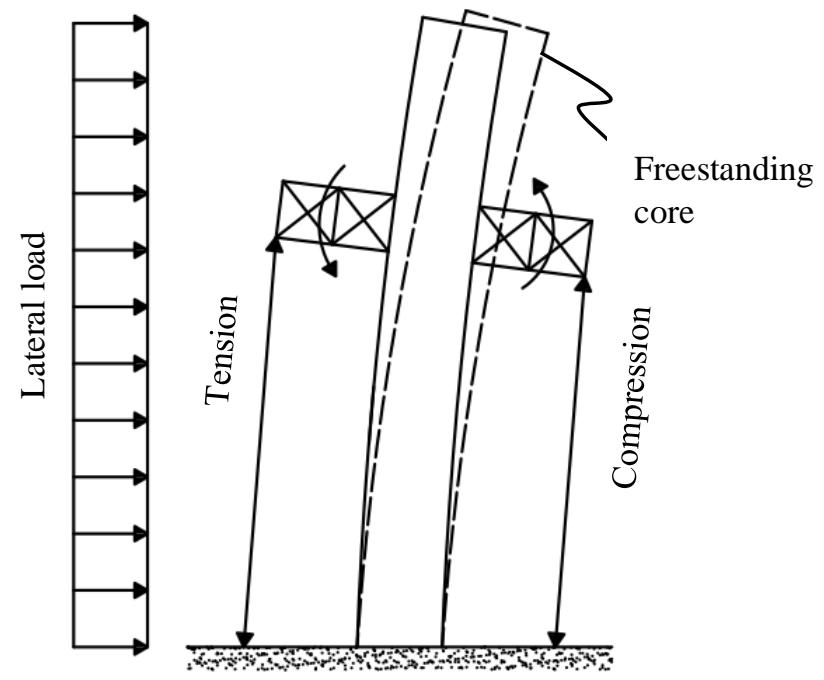

Fig. 3 Outrigger braced system behavior (updated from Ref. [8]) 
In many existing optimization studies, only the location of the equivalent spring and its stiffness have been considered as design variables, while the core resistance is assumed to be a predefined parameter. Kamgar and Rahgozar used energy method to show that the optimum locations of belt truss and outrigger systems in tall buildings can reduce roof displacement and axial forces. ${ }^{[9]}$ In another research, Kamgar and Rahgozar used critical excitation method to determine the best location of belt truss system while calculating the minimum required distance between two adjacent buildings based on roof displacement. ${ }^{[10]}$ In the study done by Lee and Tovar, the optimal placement of outriggers was determined by means of topology optimization ${ }^{[11]}$; the external work was selected as the objective function, and outriggers were distributed so that this quantity was minimized. Chen et al. proposed a genetic-based algorithm to find the optimal location of outriggers, considering both uniform and non-uniform properties for the core and perimeter frame structures. ${ }^{[12]}$ In another study by Chen and Zhang, the number and locations of outriggers were investigated through a multi-objective optimization framework, by adopting the core base moment and the top drift of the building as objective functions. ${ }^{[8]}$ Using another approach, Zhou et al. developed an inter-story drift-based method for deriving the optimal location of outriggers. ${ }^{[13]} \mathrm{Kim}$ introduced an optimization problem with mixed variables, i.e. integer and real values associated to the outrigger location and its area, respectively ${ }^{[14]}$; the top displacement was selected as the only constraint, and the problem was tackled using nonlinear programming. In the study by Park et al., a design method for minimizing the volume of core wall, outrigger, and peripheral columns was put forward based on a genetic algorithm. ${ }^{[15]}$ Finally, a hand-calculation method, considering simultaneously gravity and lateral loadings, was proposed by Balling and Lee for the optimization of outrigger braced skyscrapers to be used in the early stage of design. ${ }^{[16]}$

The design of tall buildings is mainly governed by the stiffness rather than the strength, and a proper candidate for the objective function is the external work (compliance), which is closely related to the overall stiffness of the structure. In this approach, known as the minimum-compliance method, the external work is minimized for a given amount of material; as a result, the total structural stiffness is maximized. It has been proven by Christensen and Klarbring that in a structure configuration obtained from this optimization problem, the specific strain energy is uniformly distributed throughout the design domain, unless one of the design constraints is violated ${ }^{[17]}$. in particular, for beam-like structures, this optimality criterion gives rise to a uniform curvature distribution along the beam length. ${ }^{[18-22]}$ Connor and Laflamme introduced constant curvature as an ideal performance feature for a tall structure, and the lateral stiffness was computed by enforcing this requirement. ${ }^{[23]}$ Inspired by such an approach, in this paper, the uniform curvature deformation (UCD) is selected as the desired performance objective for a tall building, and the element sizes are specified so that this predefined global deformation mode occurs. It is worth observing that Moon et al. developed a rather similar method for the uniformization of the bending and shear deformations of 
braced tube tall buildings. ${ }^{[24]}$ Karami Mohammadi et al. ${ }^{[25]}$ and Hajirasouliha and Moghaddam ${ }^{[26]}$ also investigated the problem of optimum strength distribution in shear buildings to reach a uniformly distributed story drift, proposing methods for the optimization of the structural dynamic response. In particular, Hajirasouliha and Moghaddam mention that "it can be concluded that a status of uniform deformation is a direct consequence of the optimum use of material". ${ }^{[26]}$ Moghaddam and Hajirasouliha proposed an iterative optimization procedure where the structural properties are modified by gradually shifting inefficient material from strong to weak areas of the structure. ${ }^{[27]}$ This process is continued until a state of uniform deformation is achieved. In another pragmatic approach, Hajirasouliha and Pilakoutas investigated the effects of different damage criteria, height-wise irregularity, and site soil classification to develop the optimum design of shear buildings. ${ }^{[28]}$ The concept of uniform distribution of deformation was then proposed by Nabid et al. ${ }^{[29]}$ as a tool for optimum design of passive dampers (friction-based dampers) in structures under seismic excitations.

A uniform deformation design method (UCD in particular) will be proposed in the current study as a design tool for the preliminary design of outrigger-braced structures, where the core and the outrigger interaction escalates the complexity of the problem of uniform distribution of deformation. In addition to this complexity, there are several design variables to deal with including: outrigger-belt location, $\bar{x}_{s}$, exterior column sectional area, $A$, and bending stiffness of the core, $D$. These variables would be simultaneously determined through the proposed design algorithm by enforcing the curvature to be identical at all points, yet its value is minimized; meanwhile the displacement and stress constraints are imposed. For the sake of computational convenience, two measures have been taken. First, some non-dimensional parameters are defined in advance and the main design variables are determined at the end of the procedure. Second, stress and displacement constraints are not initially taken into account, and the stiffest configuration is sought for an arbitrary amount of material $D_{U}$; thereafter, the value of $D_{U}$ is determined by imposing the stress and displacement constraints.

Before proceeding with the main problem, the effect of a UCD design on the stress distribution of a beam-like structure is investigated in the next section. The result of this section will be used in the numerical example for validating the results.

\section{Stress distribution in a UCD-based designed beam-like structure}

Uniform curvature deformation (UCD) of a beam-like structure (adopted here for modeling the core structure) gives rise to a uniform distribution of the normal stresses in the points located in the same fibers (longitudinal lines). In order to prove that, a differential beam element in pure bending is depicted in Fig. 4. 


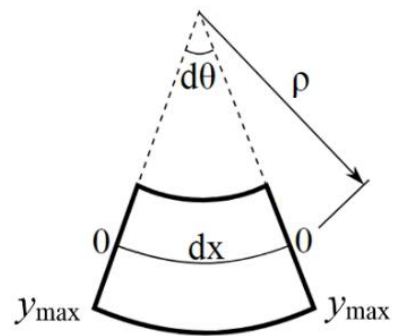

Fig. 4 A differential beam element in pure bending

where $\rho$ is the radius of curvature. The curvature $u^{\prime \prime}$ is defined as the second derivative of lateral displacement which is inversely proportional to $\rho\left(u^{\prime \prime}=1 / \rho\right)$. According to Gere and Timoshenko, longitudinal strain is proportional to the curvature. ${ }^{[30]}$ In particular, the maximum longitudinal strain, which occurs at the maximum distance from the neutral axis $\left(y_{\max }\right)$, is proportional to the curvature, as $\varepsilon_{\max }=-u^{\prime \prime} y_{\max }$. On the other hand, for linearly elastic materials, Hooke law gives $\sigma_{\max }=E \varepsilon_{\max }$, where $E$ is the modulus of elasticity. Therefore, the following relation between maximum stress and curvature is valid:

$$
\sigma_{\text {max }}=-E u^{\prime \prime} y_{\text {max }}
$$

According to Eq. (1), the maximum stress $\sigma_{\max }$ acting in the fiber at a distance $y_{\max }$ from the neutral axis would be constant along the length, if the curvature $u$ " is kept constant. In this study it is assumed that the cross-sections of the core (bending element) are the same throughout the building elevation, and, consequently, the core frame is at an identical distance $y_{\max }$ from the neutral axis at all levels, Fig. 5. Therefore, if one keeps the curvature constant, the stress would be uniformly distributed along the core. It is possible to make the curvature constant by properly adjusting the core elements' strength. This strategy will be explored in the following sections.

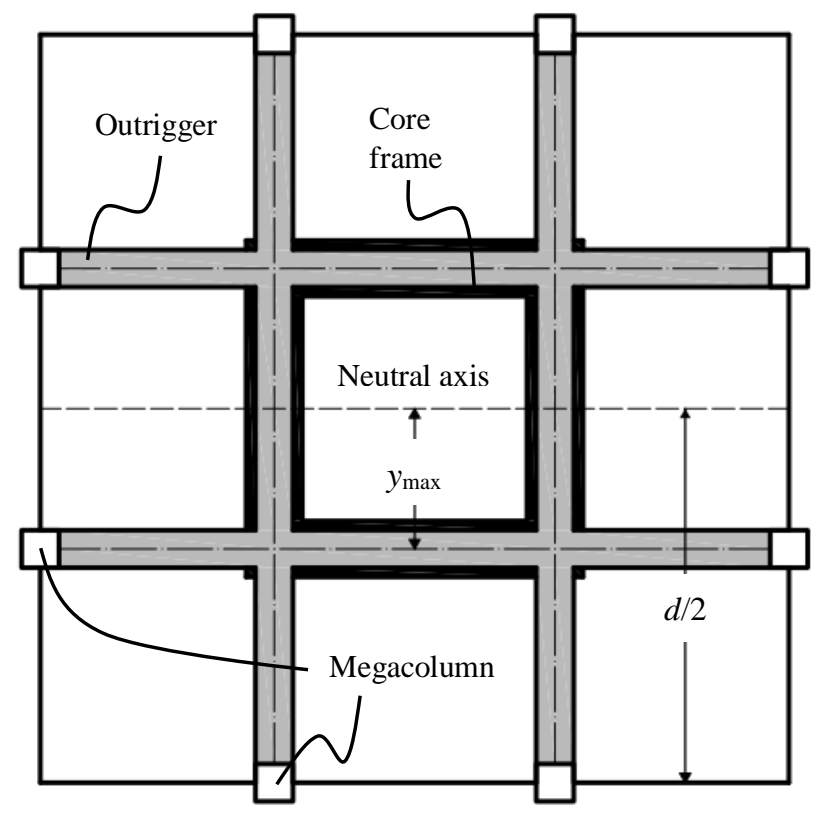


Fig. 5 Typical plan of the structure at the outrigger elevation (updated from Ref. [15])

\section{Problem formulation, optimization and design}

\subsection{Structural modeling}

A simplified model for the outrigger-equipped system is shown in Fig. 2. it consists of a continuous vertical cantilever, outer columns, and horizontal arms, which represent core structure, peripheral frame, and outriggers, respectively. The Euler-Bernoulli beam model is adopted for simulating the major motion of the core. ${ }^{[31]}$ Other models that take shear effects into accounts can simulate more precisely the performance of the structure ${ }^{[7,32]}$, as compared to the proposed method. However, as the outrigger systems are usually used in super-tall buildings with aspect ratios larger than, say 10, the shear effects fade away. The following assumptions are made in the proposed method:

- All structural members have linear elastic behavior.

- Exterior columns' sectional properties are uniformly distributed.

- Outriggers and belt trusses exhibit infinitely high flexural rigidity.

- The core connection to the base is clamped, and the outriggers are rigidly attached to the core structure. In addition, the exterior columns are connected to the belt trusses and the base via pin joints; thus, they only bear axial forces.

- The coordinate system origin is located at the top, and the positive $x$-axis is directed downward, Fig. 2. The total structural height, outrigger-belt elevation, and lateral displacement are denoted by $H, x_{s}$, and $u$, respectively.

The effect of the outrigger and exterior columns is simulated in the model by means of an equivalent spring located at the outrigger level $x_{\mathrm{s}} \cdot{ }^{[33]}$ This spring induces a concentrated reversal moment $M_{\mathrm{s}}$ in the core, Fig. 6, thus reduces the moment generated by lateral loads in the pure cantilever core.
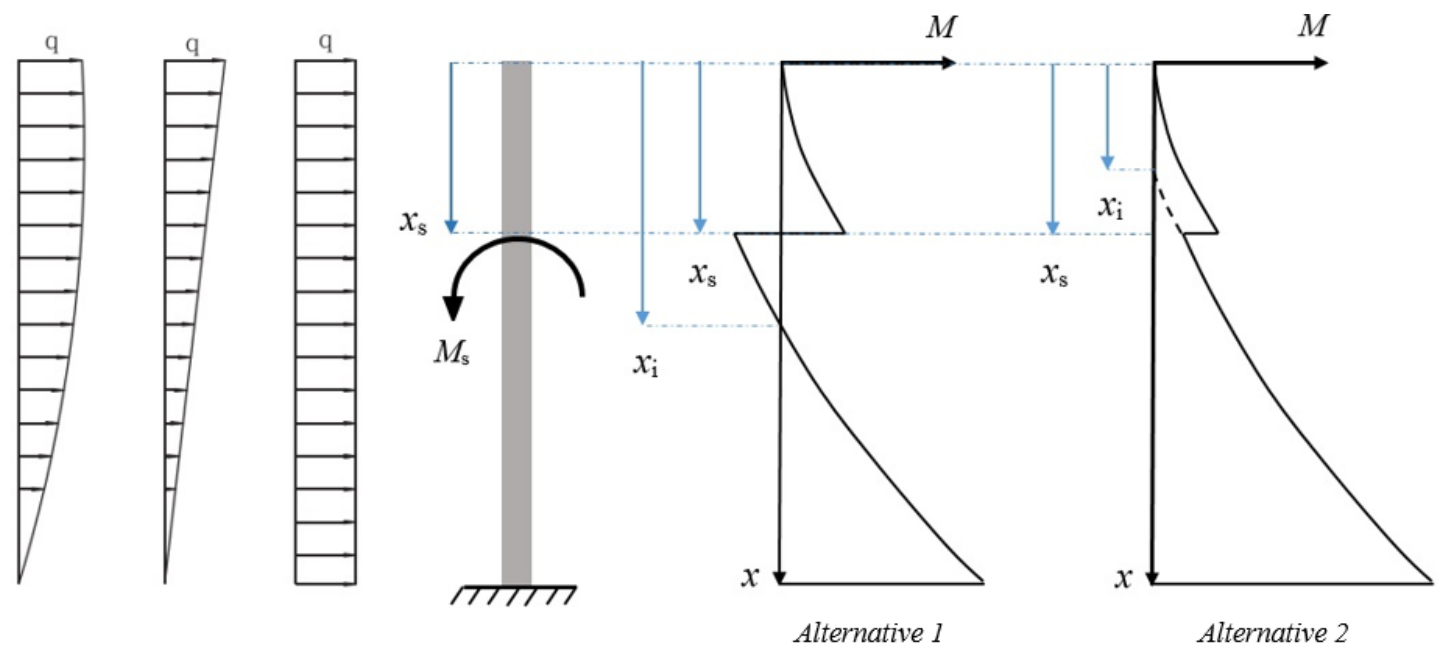

Fig. 6 The effect of outrigger system on the moment diagram 
Depending on the location and stiffness of the spring, either Alternative 1 or 2 in Fig. 6 might result for the moment diagram. However, having examined both alternatives in this study, it was observed that only Alternative 1 happens in the optimal states. Therefore, all equations in the followings are formulated only with reference to the Alternative 1; to be concise, the formulations related to Alternative 2 are omitted. Considering the three loading patterns shown in Fig. 6, uniform, triangular, and quadratic load, the moment function in terms of the non-dimensional variable $\bar{x}=x / H$ would be:

$$
M(\bar{x})= \begin{cases}M_{1}=M_{\text {max }} \bar{m}(\bar{x}) & 0<\bar{x}<\bar{x}_{s} \\ M_{2}=M_{\text {max }} \bar{m}(\bar{x})-M_{s} & \bar{x}_{s}<\bar{x}<1\end{cases}
$$

The parameters $M_{\max }$ and $\bar{m}$, named as maximum moment and relative moment, respectively, are presented in Table 1 for each loading pattern.

Table $1 M_{\max }$ and $\bar{m}$ for different loading patterns

\begin{tabular}{lcc}
\hline & $M_{\max }$ & $\bar{m}(\bar{x})$ \\
\cline { 2 - 3 } Uniform & $q H^{2} / 2$ & $\bar{x}^{2}$ \\
Triangular & $q H^{2} / 3$ & $(3 / 2) \bar{x}^{2}-(1 / 2) \bar{x}^{3}$ \\
Quadratic & $5 q H^{2} / 12$ & $(6 / 5) \bar{x}^{2}-(1 / 5) \bar{x}^{4}$ \\
\hline
\end{tabular}

According to Fig. 6 (Alternative 1), there is an inflection point $x_{i}$ under the belt location where the curve changes from concave to convex, or the moment approaches zero, i.e. $M_{2}\left(\bar{x}_{i}\right)=0$. At this condition, the spring moment, $M_{\mathrm{s}}$ can be obtained as:

$$
M_{s}=M_{\max } \bar{m}\left(\bar{x}_{i}\right)
$$

which allows the moment equation to reduce to:

$$
M(\bar{x})=M_{\max } \begin{cases}\bar{m}(\bar{x}) & 0<\bar{x}<\bar{x}_{s} \\ \bar{m}(\bar{x})-\bar{m}\left(\bar{x}_{i}\right) & \bar{x}_{s}<\bar{x}<1\end{cases}
$$

\subsection{Design problem formulation}

Among different stiffness-based methods, the minimum-compliance formulation is one of the most effective strategies. This approach proposes the compliance ${ }^{[17,34]}$ (the work done by external loads) or natural frequencies ${ }^{[35]}$ in static or dynamic problems, respectively, as the objective or constraint criteria to construct a standard optimization problem, aimed at defining the optimal distribution of a given amount of material, $D_{U}$, in the design domain. In fact, the compliance formulation seeks among different design schemes with equal material volume the one that makes the structure as stiff as possible. It was demonstrated by Christensen and Klarbring that optimal structures obtained by this approach have the property that a particular specific strain energy is constant throughout the structure. ${ }^{[17]}$ This problem was specialized for tall buildings, modeled as a beam element, by Alavi et al. ${ }^{[18,19]}$, and Alavi and Rahgozar ${ }^{[20,}$ ${ }^{21]}$ where it was shown that the optimality state for such cases is equivalent to the UCD design. Adopting 
the UCD method for the core structure design implies a constant curvature deformation mode; based on this desired performance, the core stiffness should be determined. Mathematically, the design problem of the core is defined as:

$$
\begin{array}{ll}
\text { Find } D & \\
\text { so that: } & u^{\prime \prime}= \pm C \\
\text { subject to: } & \int_{0}^{1} D \mathrm{~d} \bar{x}=D_{U}
\end{array}
$$

where, $u^{\prime \prime}$ is the curvature, and $C$ is a positive constant value. The core structure is modeled as a continuous beam member, and its bending stiffness $D(D=E I)$ is selected as the design variable and constrained to the upper bound $D_{U}$. In fact, $D_{U}$ implicitly represents the amount of construction material. The problem (4) seeks a pattern for distributing a limited amount of material $\left(D_{U}\right)$ in the design domain that results in a uniform-curvature deformation mode. The value of $D_{U}$ will be determined at the end, by imposing the stress and displacement constraints.

In addition to uniformizing the curvature, it is more efficient to minimize its absolute value $C$ by properly setting additional design variables. For this purpose, the rotational stiffness and location of the equivalent spring, $k_{s}$ and $\bar{x}_{s}$, respectively, can be selected as the other design variables. According to Taranath, $k_{s}$ is itself a function of the spring location $\bar{x}_{s}{ }^{[5]}$ :

$$
k_{s}=\frac{A E d^{2}}{2 H\left(1-\bar{x}_{s}\right)}
$$

where $E$ and $A$ are modulus of elasticity and sectional area of the peripheral columns, and $d$ is the distance between them, Fig. 2. It should be noted that Eq. (5) is valid when the flexural rigidity associated with the beam-like outrigger is infinitely high, a reasonable assumption for the initial evaluation of the equivalent spring system suitable for the preliminary design stage. ${ }^{[5]}$ In the study conducted by Kamgar and Rahgozar, the flexibility of the outrigger is investigated through numerical evaluations ${ }^{[36]}$; and in the study by Costanzo, a pragmatic method is proposed for detailed design of braces of outrigger stories. ${ }^{[37]}$ However, for the sake of convenience and preserving the analytical approach, it is assumed herein that the outrigger is infinitely flexural-rigid. In fact, Eq. (5) represents a constraint between two variables $k_{s}$ and $\bar{x}_{s}$. Instead of dealing with $k_{s}$, it is more convenient to introduce a non-dimensional variable and set up the problem based on it. By defining the new dimensionless parameter:

$$
\bar{D}=D_{U} / D_{s}
$$

where:

$$
D_{s}=k_{s} H
$$

Eq. (6) reduces to:

$$
\bar{D}=\beta\left(1-\bar{x}_{s}\right)
$$

where: 


$$
\beta=\frac{2 D_{U}}{A E d^{2}}
$$

The non-dimensional parameter $\beta$, named as the relative stiffness, is selected as the new variable, to be considered in addition to $\bar{x}_{s}$ and $D$; accordingly, the constraint expressed by Eq. (6) is now given by Eq. (8). The modified version of problem (4) considering the new design variables and minimization of the curvature would be:

$$
\begin{array}{ll}
\text { Find } D, \bar{x}_{s} \text { and } \beta & \\
\text { so that: } & u^{\prime \prime}= \pm C \\
& C \text { is minimized } \\
\text { subject to: } & \int_{0}^{1} D \mathrm{~d} \bar{x}=D_{U} \\
& \bar{D}=\beta\left(1-\bar{x}_{s}\right)
\end{array}
$$

\subsection{Uniformization of the curvature}

In a beam element, the internal moment and resultant curvature are related as $u^{\prime \prime}=M / D$, where $D$ is the flexural stiffness. ${ }^{[30]}$ Since $D$ is a positive parameter, $u^{\prime \prime}$ and $M$ have the same sign. Enforcing this fact on the moment diagram presented in Fig. 6 (Alternative 1), the desired condition $u^{\prime \prime}= \pm C$ presented in problem (10) reduces to:

$$
u^{\prime \prime}= \begin{cases}C & 0<\bar{x}<\bar{x}_{s} \\ -C & \bar{x}_{s}<\bar{x}<\bar{x}_{i} \\ C & \bar{x}_{i}<\bar{x}<1\end{cases}
$$

Imposing this condition on $u^{\prime \prime}=M / D$ and utilizing Eq. (3) for $M, D$ is determined as:

$$
D=\frac{M_{\max }}{C} \begin{cases}\bar{m}(\bar{x}) & 0<\bar{x}<\bar{x}_{s} \\ -\left[\bar{m}(\bar{x})-\bar{m}\left(\bar{x}_{i}\right)\right] & \bar{x}_{s}<\bar{x}<\bar{x}_{i} \\ \bar{m}(\bar{x})-\bar{m}\left(\bar{x}_{i}\right) & \bar{x}_{i}<\bar{x}<1\end{cases}
$$

The achieved formulation for $D$ is required to satisfy the upper bound $D_{U}$ presented in problem (10). Enforcing this constraint on Eq. (12) leads to:

$$
C=\frac{M_{\max }}{D_{U}} \alpha
$$

where:

$$
\alpha=\left[\int_{0}^{\bar{x}_{s}} \bar{m}(\bar{x}) d \bar{x}-\int_{\bar{x}_{s}}^{\bar{x}_{i}}\left[\bar{m}(\bar{x})-\bar{m}\left(\bar{x}_{i}\right)\right] d \bar{x}+\int_{\bar{x}_{i}}^{1}\left[\bar{m}(\bar{x})-\bar{m}\left(\bar{x}_{i}\right)\right] d \bar{x}\right]
$$

Eventually, substituting the obtained equation of $C$ [Eq. (13)] into that of $D$ [Eq. (12)] gives:

$$
D=\frac{D_{U}}{\alpha} \begin{cases}\bar{m}(\bar{x}) & 0<\bar{x}<\bar{x}_{s} \\ -\left[\bar{m}(\bar{x})-\bar{m}\left(\bar{x}_{i}\right)\right] & \bar{x}_{s}<\bar{x}<\bar{x}_{i} \\ \bar{m}(\bar{x})-\bar{m}\left(\bar{x}_{i}\right) & \bar{x}_{i}<\bar{x}<1\end{cases}
$$

The equation for $D$ is a function multiplied by $D_{U}$ whose value will be determined in future. 
Obviously, $D$ depends on $\bar{x}_{i}$ in addition to the design variable $\bar{x}_{s}$. In fact, $\bar{x}_{i}$ is an additional variable, which is dependent on the design variables already defined. This dependency is generated from the compatibility condition, which should be taken into account. The rigid interconnection between the outrigger and the core requires that $\theta_{s}=\theta_{c}$, where $\theta_{s}$ and $\theta_{c}$ stand for the rotations of the equivalent spring and the core, respectively, at the interface of the outrigger and the core. Integrating $u^{\prime \prime}$ presented in (11) and imposing the fact that the slope is continuous for all points, particularly at $\bar{x}_{s}$ and $\bar{x}_{i}$, and it is zero at the clamped end, the core rotation function specified at $\bar{x}_{s}$ gives: $\theta_{c}=-C H\left(\bar{x}_{s}-2 \bar{x}_{i}+1\right)$. On the other hand, the rotation generated in the spring by the internal moment is related to its stiffness as $k_{s} \theta_{s}=-M_{s}$, which using Eq. (2) for $M_{s}$, results in: $\theta_{s}=-M_{\max } \bar{m}\left(\bar{x}_{i}\right) / k_{s}$. Therefore, the equality condition $\theta_{s}=\theta_{c}$, in which Eqs. (13), (6), (7) and (8) are used, yields:

$$
\beta\left(1-\bar{x}_{s}\right)-\frac{\alpha}{\lambda}=0
$$

where:

$$
\lambda=\frac{\bar{m}\left(\bar{x}_{i}\right)}{\bar{x}_{s}-2 \bar{x}_{i}+1}
$$

Eq. (16) represents an implicit constraint between $\bar{x}_{i}$ and the other two variables $\bar{x}_{s}$ and $\beta$.

\subsection{Minimization of the curvature}

Based on Eq. (13), the magnitude of $C$ depends on two parameters, $\bar{x}_{s}$ and $\bar{x}_{i}$, whose optimal values are those that minimize $C$, [problem (10)]. To set up the optimization problem, Eq. (13) is considered to be minimized. However the constant term $M_{\max } / D_{U}$ can be ignored, and hence $\alpha$ would be optimized as the objective function, while the constraint (16) is imposed. Therefore, the optimization problem (10) is reduced to:

$$
\begin{aligned}
& \underset{\bar{x}_{s}, \bar{x}_{i}, \beta}{\operatorname{Minize}} \alpha \\
& \text { Subject to: } \quad \beta\left(1-\bar{x}_{s}\right)-\frac{\alpha}{\lambda}=0
\end{aligned}
$$

It should be noted that, the curvature uniformization objective $u^{\prime \prime}= \pm C$ has already been satisfied by defining the stiffness function $D$ by Eq. (15). Also, the constraint $\bar{D}=\beta\left(1-\bar{x}_{s}\right)$ presented in problem (10) was satisfied in determining Eq. (16). These two facts allow the problem (10) to be presented in the simpler form of Eq. (18). As the objective function $\alpha$ does not depend on $\beta$, its optimal value is easily obtained by differentiating $C$ with respect to $\bar{x}_{s}$ and $\bar{x}_{i}$, and equating to zero, Table 2.

Table 2 Optimality conditions for $\alpha$

\begin{tabular}{ccc}
\hline & $\partial \alpha / \partial \bar{x}_{s}=0$ & $\partial \alpha / \partial \bar{x}_{c}=0$ \\
\cline { 2 - 3 } Uniform & $2 \bar{x}_{s}^{2}-\bar{x}_{i}^{2}=0$ & $2 \bar{x}_{i}^{2}\left(2 \bar{x}_{i}-\bar{x}_{s}-1\right)=0$
\end{tabular}


Triangular

$$
\frac{1}{2} \bar{x}_{i}^{3}-\frac{3}{2} \bar{x}_{i}^{2}-\bar{x}_{s}^{3}+3 \bar{x}_{s}^{2}=0
$$

$\frac{3}{2} \bar{x}_{i}\left(2-\bar{x}_{i}\right)\left(2 \bar{x}_{i}-\bar{x}_{s}-1\right)=0$

Quadratic

$\frac{1}{5} \bar{x}_{i}^{4}-\frac{6}{5} \bar{x}_{i}^{2}-\frac{2}{5} \bar{x}_{s}^{4}+\frac{12}{5} \bar{x}_{s}^{2}=0$

$\frac{4}{5} \bar{x}_{i}\left(3-\bar{x}_{i}^{2}\right)\left(2 \bar{x}_{i}-\bar{x}_{s}-1\right)=0$

For each loading case, there are two equality equations and two unknowns. Solving these two equations simultaneously gives the optimal values of $\bar{x}_{s}$ and $\bar{x}_{i}$, as presented in Table 3 . It should be noted that in all cases $\bar{x}_{s}$ is smaller than $\bar{x}_{i}$, which coincides with Alternative 1 of Fig. 6

Table 3 Optimal values for $\bar{x}_{s}$ and $\bar{x}_{i}$

\begin{tabular}{lcc}
\hline & $\bar{x}_{s}$ & $\bar{x}_{i}$ \\
\cline { 2 - 2 } Uniform & 0.5469 & 0.7735 \\
Triangular & 0.5050 & 0.7525 \\
Quadratic & 0.5243 & 0.7622 \\
\hline
\end{tabular}

Utilizing the values presented in Table 3 into the constraint of Eq. (18) makes $\beta$ equal to zero; based on Eq. (9), this condition is equivalent to an infinitely stiff spring. Therefore, as the optimal solution, the spring stiffness should be unboundedly big, and the belt location $\bar{x}_{s}$, and core stiffness $D$ are determined from Table 3 and Eq. (15), respectively. Actually, providing this condition for the spring stiffness is not possible in practice, so the effect of its flexibility is studied in the next section.

\section{Flexibility of the equivalent spring (outrigger-belt-column system)}

According to the last section, the optimal design, which minimizes the curvature $C$, is the one in which the outrigger-peripheral-column system generates an infinitely high rotational stiffness. However, this is not practical, because some degree of flexibility is afforded by the shortening and lengthening of the exterior columns. This section studies this issue by investigating the effect of $\beta$ value on the optimal location of the belt. The optimization problem is modified as:

$$
\begin{array}{ll}
\underset{\bar{x}_{s}, \bar{x}_{i}}{\operatorname{Minimize}} & \alpha \\
\text { Subject to: } & \beta\left(1-\bar{x}_{s}\right)-\frac{\alpha}{\lambda}=0
\end{array}
$$

Note that this problem does not include $\beta$ as a design variable; it is considered as a predefined parameter. In fact, if $\beta$ is given, the problem (19) can be easily solved by a numerical approach. This would be a simple task because the design variables $\bar{x}_{s}$ and $\bar{x}_{i}$ vary between 0 and 1 . Almost all discrete values in the interval $\left[\begin{array}{ll}0 & 1\end{array}\right]$ are tried and the one which produces the minimum value for the objective function is selected as the optimal solution. Indeed, the trial value is selected for $\bar{x}_{s}$, then $\bar{x}_{i}$ is determined by solving the constraint $\beta\left(1-\bar{x}_{s}\right)-\alpha / \lambda=0$ numerically, and then the objective function is computed. This procedure is repeated for different values of $\beta$ and the associated optimal $\bar{x}_{s}$ and $\bar{x}_{i}$ are determined. Using a curve fitting method 
through MATLAB ${ }^{[38]}$, the functions of $\bar{x}_{s}$ and $\bar{x}_{i}$ in terms of $\beta$ are obtained, Fig. 7. The equation of the fitting curves would be a rational one as:

$$
\bar{x}_{s}, \bar{x}_{i}=\frac{n_{1} \beta^{3}+n_{2} \beta^{2}+n_{3} \beta+n_{4}}{\beta^{4}+m_{1} \beta^{3}+m_{2} \beta^{2}+m_{3} \beta+m_{4}}
$$

where the coefficients $n_{i}$ and $m_{i}$ associated with each case are presented in Table 4. According to Fig. 7, $\bar{x}_{s}$ is always lower than $\bar{x}_{i}$, hence Alternative 1 is valid here again for the optimal state.

Table 4 Coefficients $n_{i}$ and $m_{i}$ used in Eq. (20)

\begin{tabular}{|c|c|c|c|c|c|c|c|c|c|}
\hline & & $n_{1}$ & $n_{2}$ & $n_{3}$ & $n_{4}$ & $m_{1}$ & $m_{2}$ & $m_{3}$ & $m_{4}$ \\
\hline \multirow{2}{*}{ Uniform } & $\bar{x}_{s}$ & 8.9 & 113.8 & -110.8 & 102.5 & 86.2 & 158.2 & -184.3 & 184.9 \\
\hline & $\bar{x}_{i}$ & 6.1 & 28.37 & -8.1 & 1.54 & 37.67 & 28.1 & -8.67 & 2.1 \\
\hline \multirow{2}{*}{ Triangular } & $\bar{x}_{s}$ & 6.6 & 66.2 & -59.7 & 42.5 & 63.6 & 88.9 & -106.6 & 82.5 \\
\hline & $\bar{x}_{i}$ & 5.17 & 22.36 & -8.96 & 1.69 & 35.13 & 18.31 & -9.7 & 2.27 \\
\hline \multirow{2}{*}{ Quadratic } & $\bar{x}_{s}$ & 7.7 & 86.7 & -74.5 & 64 & 72.9 & 126.6 & -132.4 & 120.5 \\
\hline & $\bar{x}_{i}$ & 5.7 & 25.12 & -9.36 & 1.57 & 36.52 & 22.51 & -10.52 & 2.08 \\
\hline
\end{tabular}

In fact, $\beta=0$ represents the rigid spring condition [see Eq. (9)]. The values of $\bar{x}_{s}$ and $\bar{x}_{i}$ associated with this condition are presented on the vertical axis in Fig. 7. Comparing these values to the ones presented in Table 3 (the rigid spring condition), it can be observed that they are almost identical, thereby validating the numerical method used here.

(a)

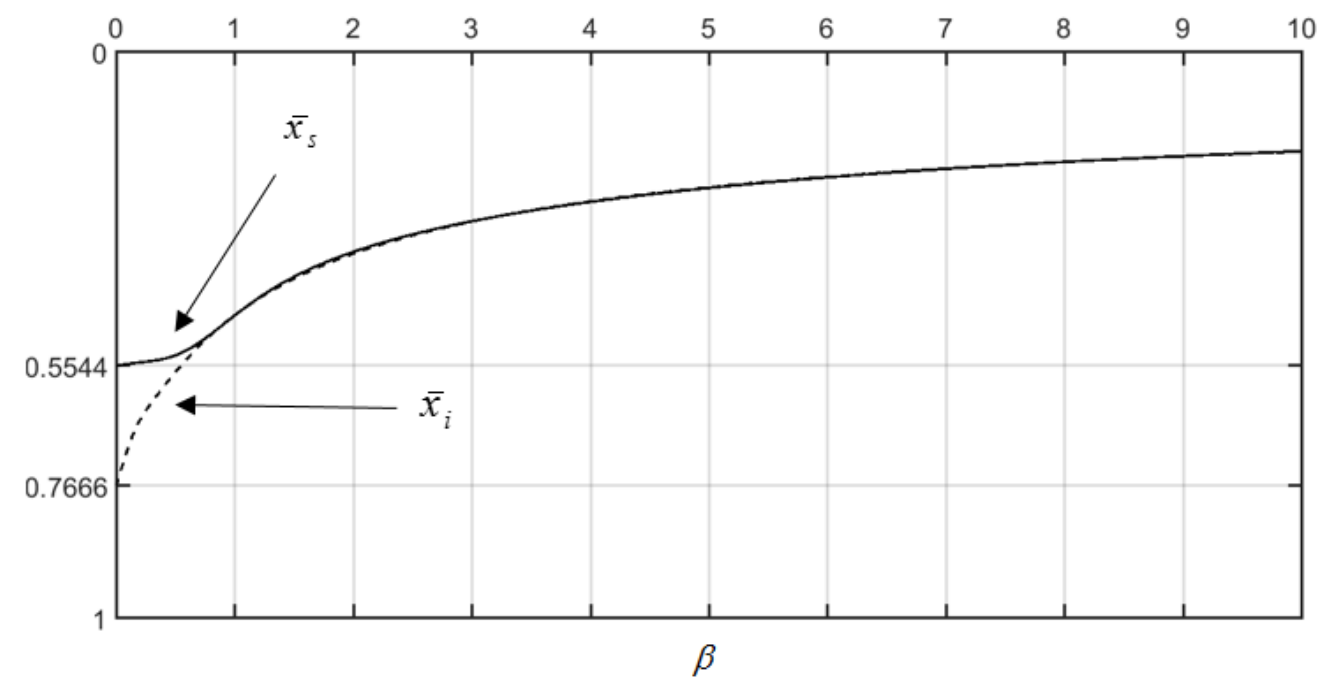


(b)

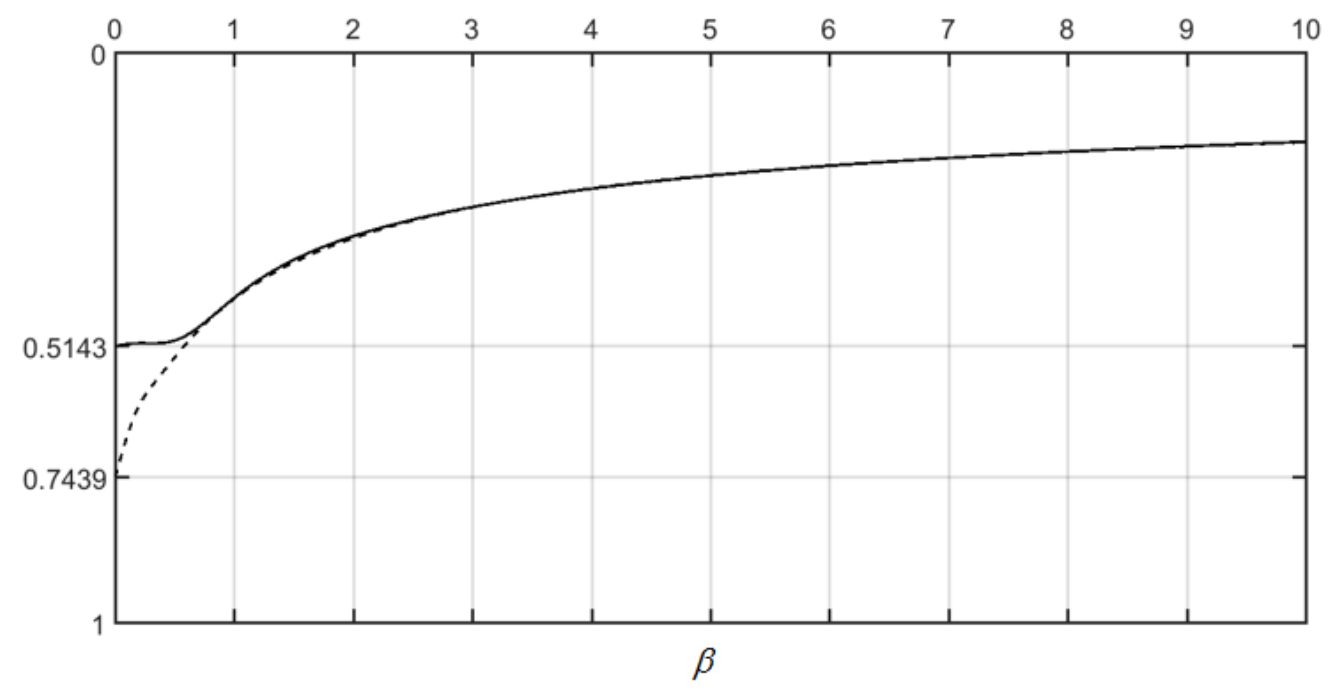

(c)

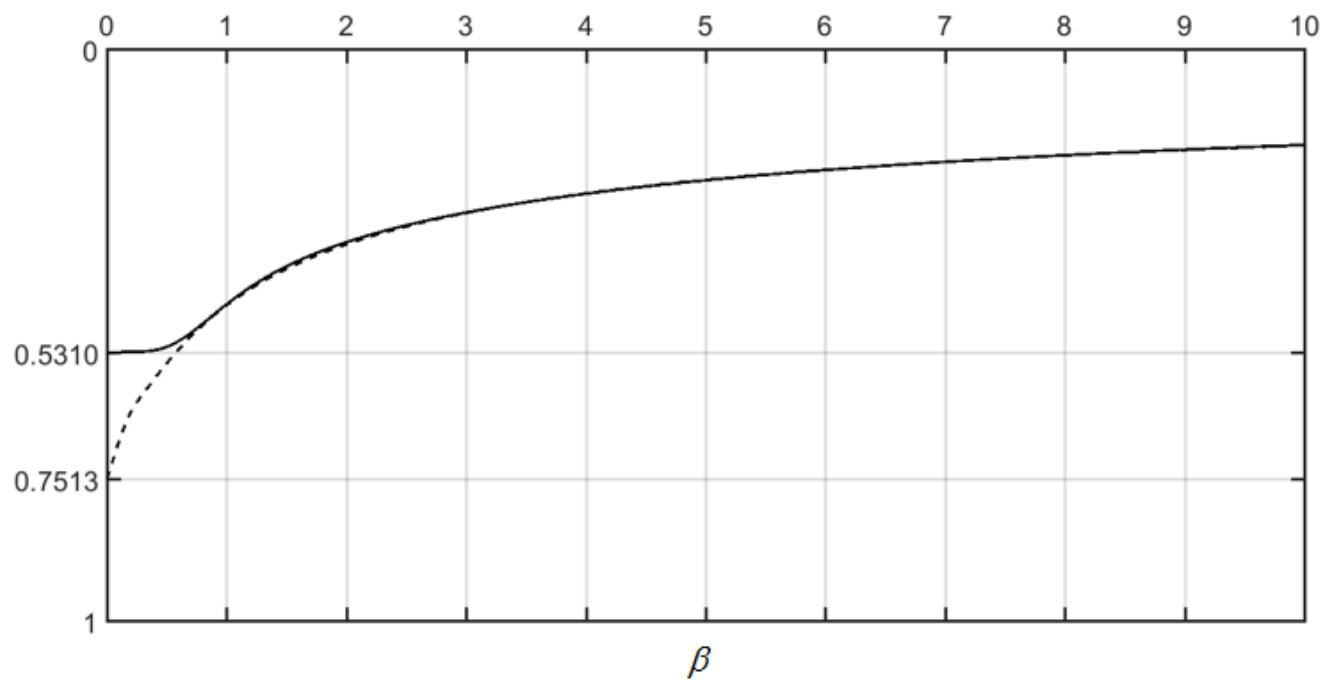

Fig. 7 The optimal location of outrigger $\bar{x}_{s}$ and inflection point $\bar{x}_{i}$ with respect to relative stiffness $\beta$;

(a) Uniform loading (b) Triangular loading (c) Quadratic loading

\section{Equalizing the normal stress between peripheral columns and the core}

Subsection 3.3 has addressed the uniformization of stresses throughout the core element for a specified $\beta$. However, this stress value might be different from the stress value in the peripheral columns. This section evaluates the value of $\beta$ that makes the normal stress in the core, $\sigma_{\text {core }}$, to be identical to the columns counterpart, $\sigma_{\text {column }}$, i.e.:

$$
\sigma_{\text {core }}=\sigma_{\text {column }}
$$

Utilizing Eq. (13) into Eq. (1), and then, using Eqs. (6), (8) and (16) sequentially, $\sigma_{\text {core }}$ can be easily expressed as:

$$
\sigma_{\text {core }}=-E\left(\frac{M_{\max } y_{\max }}{D_{s}}\right) \lambda
$$


In order to evaluate $\sigma_{\text {column }}$, the equivalent spring relations should be considered. The rotation of the spring is: $\theta_{s}=-M_{s} / k_{s}$. The rotation $\theta_{s}$ is related to lengthening (and shortening) in the distant columns: $\delta=\theta_{s}(d / 2)$. Therefore, the normal stress of the columns would be: $\sigma_{\text {column }}=E\left[\delta / H\left(1-\bar{x}_{s}\right)\right]$, where $H\left(1-\bar{x}_{s}\right)$ is the length of the columns. Subsequently, by using Eq. (2) for $M_{s}, \sigma_{\text {column }}$ is determined as:

$$
\sigma_{\text {column }}=-E\left(\frac{M_{\max } d / 2}{D_{s}}\right) \gamma
$$

where:

$$
\gamma=\frac{\bar{m}\left(\bar{x}_{i}\right)}{1-\bar{x}_{s}}
$$

Therefore, the equality condition of Eq. (21) contributes to the following relation:

$$
\bar{d} \lambda-\gamma=0
$$

where the non-dimensional variable $\bar{d}$ is defined as:

$$
\bar{d}=\frac{y_{\max }}{(d / 2)}
$$

Both $\bar{x}_{s}$ and $\bar{x}_{i}$ are functions of $\beta$ as presented in Eq. (20). Therefore, Eq. (25) contains only one variable, $\beta$, which can be computed by solving Eq. (25), provided that $\bar{d}$ is specified. It should be noted that $\bar{d}$ varies between 0 and 1 because of geometrical condition, Fig. 5. Therefore, different discrete values for $\bar{d}$ in the interval [l 1 1] are tried, and the function (25) is solved to obtain the associated value for $\beta$. Finally, by a proper curve fitting method, the function of $\beta$ in terms of $\bar{d}$ is obtained as:

$$
\beta=p_{1} \bar{d}^{4}+p_{2} \bar{d}^{3}+p_{3} \bar{d}^{2}+p_{4} \bar{d}+p_{5}
$$

where the coefficients $p_{i}$ are presented in Table 5. Accordingly, for a given $\bar{d}$, which is typically an architectural decision, the value of $\beta$ which satisfies Eq. (21) is obtained from Eq. (27).

Table 5 Coefficients $p_{i}$ used in Eq. (27)

\begin{tabular}{lccccc}
\hline & $p_{1}$ & $p_{2}$ & $p_{3}$ & $p_{4}$ & $p_{5}$ \\
\cline { 2 - 5 } Uniform & 0.792 & -0.809 & 0.569 & 0.182 & -0.006 \\
Triangular & 0.678 & -0.574 & 0.367 & 0.245 & -0.012 \\
Quadratic & 1.075 & -1.3 & 0.8 & 0.155 & -0.007 \\
\hline
\end{tabular}

In fact, the obtained $\beta$ dictates the belt location $\bar{x}_{s}$ based on Eq. (20). Investigating the function $\beta$, Eq. (27) reveals that it has a monotonic characteristic; thus, its extreme values occur at the boundary points. Substituting the boundary values 0 and 1 for $\bar{d}$ in Eq. (27), gives rise to $\beta$ equal to 0 and approximately 0.7 , respectively. According to the diagrams of Fig. 7, for $\beta \in\left[\begin{array}{ll}0 & 0.7\end{array}\right]$, the value of $\bar{x}_{s}$ is approximately constant and equal to the one associated with $\beta=0$. As a result, the optimal location of the 
outrigger $\bar{x}_{s}$ can be assumed always fixed, and equal to either the values shown on the vertical axis (associated with $\beta=0$ ), or the values presented in Table 3 .

It can be concluded that Eq. (21) always holds for any $\beta$ in the interval [0 0.7$]$, provided that the belt location is selected from Table 3; hence, it is independent of the value of $\beta$. This occurrence can be justified according to the fact that altering $\beta$ has approximately the same effect in terms of stresses induced in the columns and the core. For example, by increasing the column sectional area $A$, the normal stress in the column decreases. On the other hand, increasing $A$ would make the spring stiffer, and as a result, stress in the core also decreases; and the rate of these two reductions are approximately equal.

Although the value of $\beta$ has no effect on the optimal location of the belt, it can dictate the values of other parameters such as $A$ or $D_{U}$ based on Eq. (9). As Eq. (9) includes the two mentioned variables, one of them is redundant; thus, one of these variables should be specified and the other one is determined from this equation. However, specifying the value for any of these variables is a technical issue which is discussed in the following section.

\section{Stress and displacement constraints}

\subsection{Allowable stress}

Based on Eq. (21), the maximum normal stress in the core is always equal to that of exterior columns as long as the outrigger location is optimal. In fact, the magnitude of this stress should not be larger than the material strength, or it should be lower than a specified allowable value, $\sigma_{\text {allowable }}$. Due to the stress equality, either $\sigma_{\text {column }}$ or $\sigma_{\text {core }}$ could be controlled; however, selecting $\sigma_{\text {column }}$ is more convenient, therefore:

$$
\sigma_{\text {column }} \leq \sigma_{\text {allowable }}
$$

Recalling Eq. (23) for expressing the column stress demand, and considering Eqs. (7), (5) and (24) for $D_{s}$, $k_{s}$ and $\gamma$, respectively, the stress condition (28) results in the following requirement for column sectional area $A$ :

$$
A \geq \frac{M_{\max } \bar{m}\left(\bar{x}_{i}\right)}{\sigma_{\text {allowable }} d}
$$

By using this value for $A$ and the value for $\beta$ derived from Eq. (27) into Eq. (9), the required value for $D_{U}$ can easily be obtained, as:

$$
D_{U}=\frac{1}{2} \beta A E d^{2}
$$

\subsection{Total drift ratio limit}

Excessive displacements in high-rise structures can cause damage to non-structural elements such as cladding and façade; also, they can disrupt lifts from functioning properly. Furthermore, occupant comfort 
is closely related to the perceived movement of buildings. Therefore, it is essential to define proper criteria for limiting lateral displacements of the structure. The total drift ratio, defined as the peak lateral deflection of the structure divided by its total height, is widely accepted among experts for expressing a suitable deflection criterion. The total drift ratio is constrained to the limit $\bar{\Delta}_{\text {allowable }}$; mathematically:

$$
\frac{u_{\max }}{H} \leq \bar{\Delta}_{\text {allowable }}
$$

where $u_{\max }$ and $H$ are lateral displacement of the structure top and total structural height, respectively. In order to check this criterion, the displacement function $u$ should be determined and then specified at the top of the structure $(\bar{x}=0)$. For this purpose, the function $u$ " presented in Eq. (11) is integrated twice, and the boundary conditions are imposed to obtain $u$. The expression obtained for $u$ is a function of $\bar{x}, \bar{x}_{s}$ and $\bar{x}_{i}$. Substituting zero for $\bar{x}, u_{\max }$ is determined as:

$$
u_{\max }=\delta C H^{2}
$$

where $\delta$ is:

$$
\delta=\bar{x}_{s}^{2}-\bar{x}_{i}^{2}+\frac{1}{2}
$$

Substituting the Eq. (13) for $C$ into Eq. (32), and using Eq. (31), the following equation is obtained as the limited value for $D_{U}$ :

$$
D_{U} \geq \delta \alpha \frac{M_{\max } H}{\bar{\Delta}_{\text {allowable }}}
$$

Using this expression for $D_{U}$ into Eq. (9), the associated $A$ is obtained as:

$$
A=\frac{2 D_{U}}{\beta E d^{2}}
$$

The relations obtained for $A$ and $D_{U}$ in this section and the ones derived in previous section produce the same $\beta$, which is determined from Eq. (27). The value of $D_{U}$ and $A$ derived here should be compared with the counterpart obtained in the previous section, and the largest one should be selected as the design solution. Obviously, if the quantities of this section are selected as the design solution, the total drift ratio limit given by Eq. (31) is the governing criterion, and stress is within the acceptable range defined by Eq. (28); the opposite condition occurs for stress and total drift limits if the parameters values of the previous section are chosen. Eventually, the selected $D_{U}$ is substituted into Eq. (15) to determine the optimal stiffness of the core.

\section{Design algorithm}

A 10-step algorithm, followed by a design flowchart (Fig. 8), for the optimal design of outrigger-braced structures based on the proposed method is outlined in the following. As a preliminary step, initial values for the design parameters should be specified as inputs, namely: the geometrical parameters $y_{\max }$ and $d$, which are specified according to architectural decisions; $E, \sigma_{\text {allowable }}$ and $\bar{\Delta}_{\text {allowable }}$, which are structural 
requirements; $M_{\max }$ and $\bar{m}$ should be specified based on Table 1 according to the loading pattern. Then, the following quantities are sequentially determined:

1. $\bar{x}_{s}$ from Table 3

2. $\bar{d}$ from Eq. (26)

3. $\beta$ from Eq. (27)

4. $\bar{x}_{i}$ from Eq. (20)

5. $\alpha$ from Eq. (14)

6. $\delta$ from Eq. (33)

7. The minimum value of $A$ from Eq. (29) and associated $D_{U}$ from Eq. (30)

8. The minimum value of $D_{U}$ from Eq. (34) and associated $A$ from Eq. (35)

9. The larger values obtained from steps 7 and 8 are selected for $D_{U}$ and $A$

10. $D$ from Eq. (15)

The values of $\bar{x}_{s}, A$ and $D$ derived from the above steps are the optimal values for the outriggerbelt location, peripheral column sectional area, and core stiffness function, respectively. 


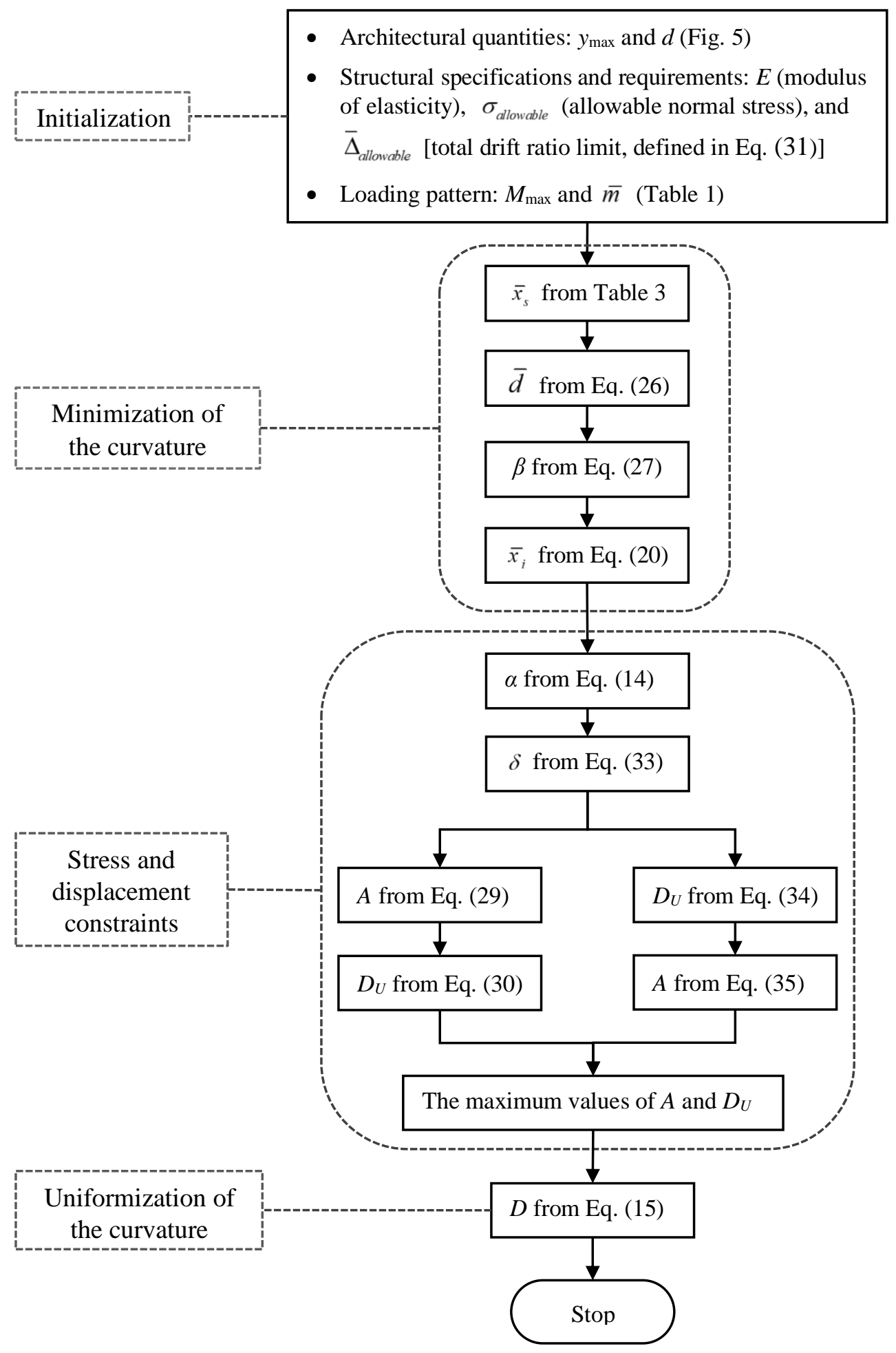

Fig. 8 The design flowchart 


\section{Numerical example}

In the following, the preliminary design of a core-columns-outrigger system for a 60 -story building subjected to uniform lateral load is carried out according to the presented algorithm. Steel framing, equipped with a two-story diagonal outrigger-belt system, is selected for the core structure. The core frame has columns closely spaced at $2.5 \mathrm{~m}$, Fig. 9 , for maximizing the bending rigidity. In order to control shear deformations, strong diagonal elements extending over multiple stories are inserted in the core frame. This structural system allows the design of the core to focus on the pure bending component, as is done in the proposed method. The exterior columns, which should bear only axial forces, are connected to the base and to the belt trusses by means of pin joints. Initial values and major data, including the building information, material properties, and loading value, are given in Table 6.

Table 6 Initial data

\begin{tabular}{llll}
\hline Half dimension of core frame plan $y_{\max }$ & $10 \mathrm{~m}$ & Lateral load intensity $q$ & $100 \mathrm{kN} / \mathrm{m}$ \\
Half dimension of exterior frame plan $\mathrm{d} / 2$ & $25 \mathrm{~m}$ & Modulus of elasticity $E$ & $200 \mathrm{GPa}$ \\
Total structural height $H$ & $210 \mathrm{~m}$ & Allowable stress $\sigma_{\text {allowable }}$ & $250 \mathrm{MPa}$ \\
Maximum moment $M_{\max }$ & $q \mathrm{H}^{2} / 2$ & Total drift ratio limit $\bar{\Delta}_{\text {allowable }}$ & $1 / 450$ \\
Relative moment $\bar{m}$ & $\bar{x}^{2}$ & & \\
\hline
\end{tabular}

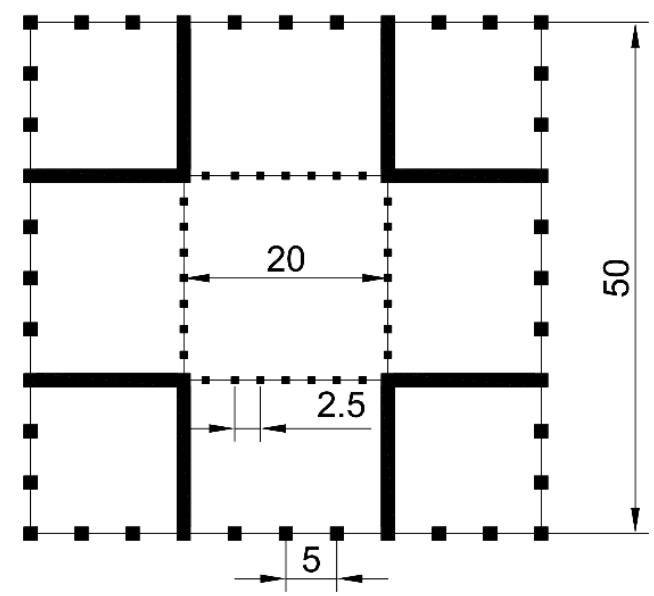

Fig. 9 Plan of the structure at the outrigger elevation

\subsection{Structural design}

The design algorithm gives the optimal values of: outrigger position along elevation, exterior columns dimensions, and bending stiffness of the core $D$. To compute the sizes of the core elements from the value obtained for $D$, two more relations are needed. First, it is assumed that the core can be modeled by means of a hollow box section of thickness $t$; thus, with the bending strength being $D=E I_{0} t$ (where, approximately, $\left.I_{0}=(16 / 3) y_{\max }^{3}\right)$, and given $D, E$, and $I_{0}$, the value of $t$ can be derived. Second, the cross-section areas of 
columns are computed based on the relation presented by Kwan ${ }^{[39]}$, as $A_{c}=t . s$, where $s=2.5 m$ is the column spacing.

The design is carried out based on the proposed algorithm and these two equations. The final results, in terms of the required columns' sectional area for the core and peripheral frame, are presented in Fig. 10. Also, the optimal value for outrigger-belt location is determined as:

Outrigger-belt distance from the top: $114.8 \mathrm{~m}$

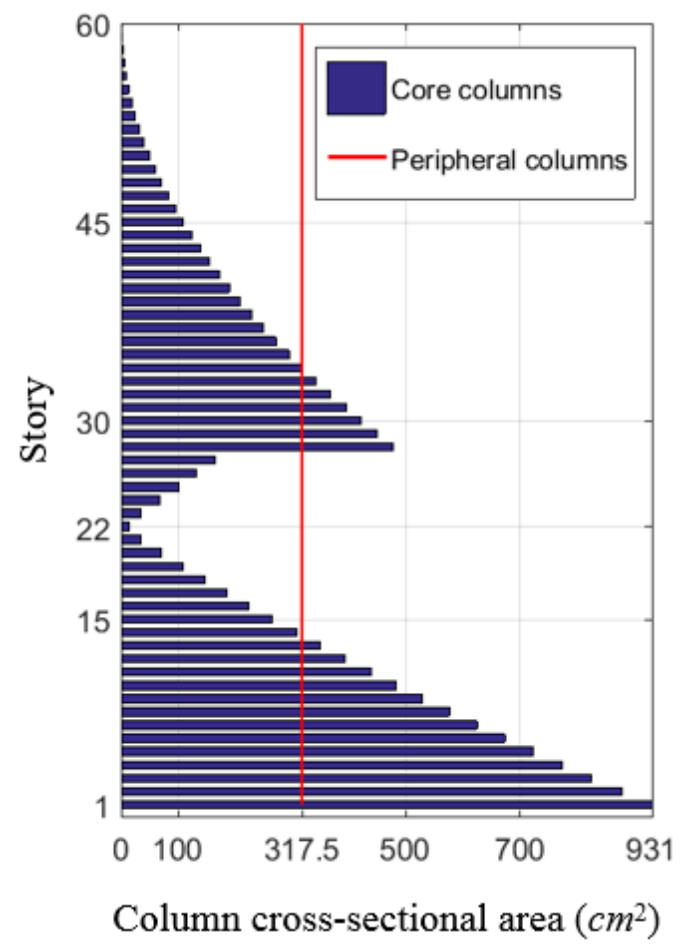

Fig. 10 Required sectional area for the core and peripheral columns

The displacement requirement has dominated the design. Therefore, the area globally required for the exterior columns is determined based on Eq. (35); then, the obtained value is divided by 11, i.e. the number of columns located along one side of the plan (Fig. 9), giving $317.5 \mathrm{~cm}^{2}$ for the cross-section area of each perimeter column.

The outrigger-belt is located at $114.8 \mathrm{~m}$ from the top, which corresponds to the $27^{\text {th }}$ story; here a jump in the value of the cross-sectional area of the core columns can be observed in Fig. 10. This is due to the effect of the concentrated moment induced at this level by the outrigger-belt and exterior columns interaction, which causes a sudden reduction in the core bending moment. ${ }^{[40]}$ Also, the inflection point is located at the $22^{\text {nd }}$ story, where the direction of curvature changes; accordingly, the magnitude of the core bending moment at this story approaches zero, and, as a result, the required sectional area is almost zero, Fig. 10. It should be noted that the member sizes are specified here considering only transversal loads. If 
one takes vertical loads (such as gravity load) into account, the sizes of elements determined based on which should be added to the values presented in Fig. 10. It worth noting, when it comes to seismic design, the ability of uniform-deformation-design approach adopted here is sensitive with respect to gravity loads. Hajirasouliha et al. showed that the efficiency of this method would considerably reduce in seismic design when gravity loads are taken into account. ${ }^{[41]}$

\subsection{Software analyses and results}

The software ETABS ${ }^{[42]}$ is used to verify the effectiveness of the procedure and to quantify the accuracy of the results. For this purpose, a finite element model of the 60-story structural system is built (Fig. 11), based on the information of Table 6 and columns dimensions presented in Fig. 10, while a uniform load pattern of $100 \mathrm{kN} / \mathrm{m}$ is applied. The outrigger-belt system extends over two stories, 27 and 28, with very stiff diagonal and chord elements in order to be in line with the assumption of infinitely high rigidity.

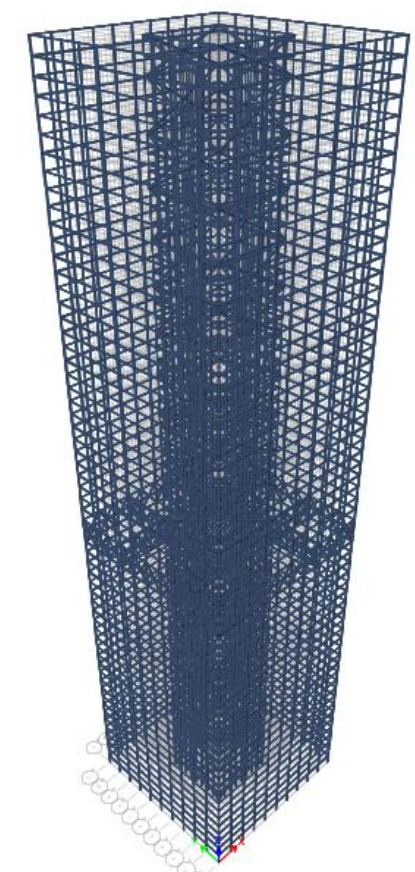

Fig. 11 Structural model used in ETABS ${ }^{[42]}$

As mentioned before, the design was dominated by displacement requirement, $\bar{\Delta}_{\text {allowable }}$. Therefore, it is anticipated that this constraint to be closely satisfied in the analyze procedure, and that the normal stresses, arising in the columns of both core and perimeter frame, to be lower than the upper bound $\sigma_{\text {allowable }}$. Furthermore, according to second section, the normal stresses should be uniformly distributed along the core. Static analysis of the model reveals that the roof displacement is $530 \mathrm{~mm}$, approximately equal to H/400, Fig. 12 (a), which is slightly larger than the required value $467 \mathrm{~mm}$ given by $\bar{\Delta}_{\text {allowable }}(\mathrm{H} / 450)$. 
Therefore, the displacement constraint is satisfied with a relative error of $13.5 \%$. The normal stresses are also computed along the height. The absolute value of the normal stresses in the columns of one side are computed and then divided by the allowable value $\sigma_{\text {allowable }}$, and these relative values are presented in Fig. 12 (b). Apparently, the normal stress in all columns are significantly lower than the allowable value, which demonstrates that the design problem is governed by the stiffness. The normal stress is almost uniformly distributed along the core with average magnitude very close to that of the peripheral columns, which validates the proposed method. However, some discrepancies between the numerical results and the outcomes of the proposed method can be observed, which can be attributed to the following approximations: (a) the proposed method is founded on a continuous approach, while the computer model is set up by discrete elements; (b) in the numerical model, the uniform lateral load is simulated by some point loads along the height of the structure; (c) the proposed method neglects the effects of shear deformation, while the computer model automatically accounts for them.

Having explored the distribution of normal stresses in the core columns along the height, it was observed that the compression (tension) stress changes to tension (compression) one at story 22 . This means that the inflection point is located at this story, which was predicted by the proposed method.

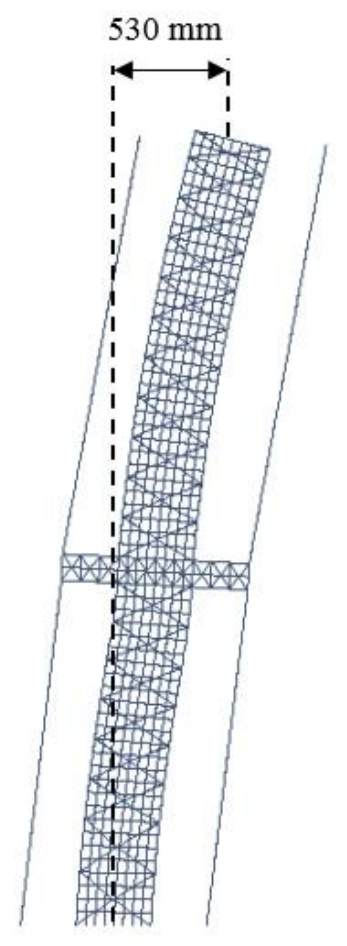

(a)

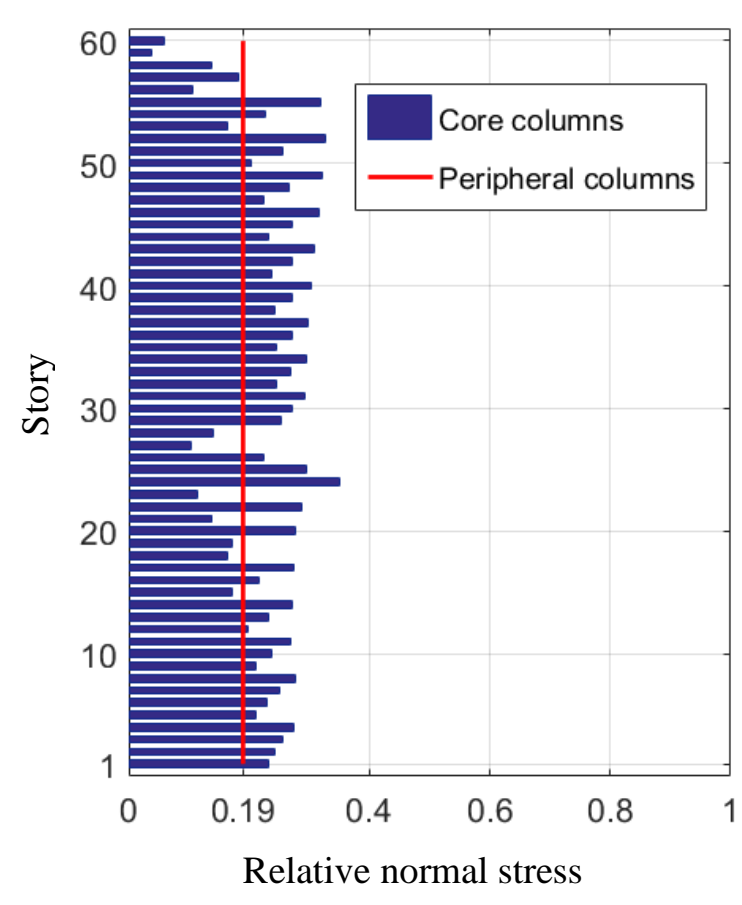

(b)

Fig. 12 Software analyses outputs: (a) roof displacement (b) relative normal stress with respect to allowable normal stress $\sigma_{\text {allowable }}$ 


\section{Conclusions}

A parametric-based method suitable for the initial design of tall buildings equipped with an outrigger was proposed. The flexural stiffness of the core was selected as one of the design variables, and it was determined by requiring the curvature to be kept constant. The other two design variables, the peripheral column dimensions, and the outrigger-belt location, were evaluated by minimizing the magnitude of the curvature, and by imposing displacement and/or stress constraint. The design procedure was illustrated by means of a convenient algorithm which does not require iteration. The algorithm first predicts which constraints will govern the design, then computes the optimal values for the element sizes. A numerical example was provided to demonstrate the effectiveness and accuracy of the method in practice; the following major conclusions are drawn.

- The analysis outputs in the numerical example revealed that the normal stress is distributed almost uniformly along the structure's height, or equivalently, the curvature is constant throughout the design domain, thereby validating the proposed method.

- It was shown that the roof displacement of the structure in the numerical example approaches the allowable design value with a slight error of $13.5 \%$; on the other hand, the strength requirement is widely satisfied, with the normal stresses far lower than the permissible value. This condition demonstrates how displacement criteria govern the design of tall buildings.

- Investigating the design diagram reveals that the method predicts accurately the location of the inflection point, where the smallest dimension is needed for the core elements.

- Due to a reversal moment at the outrigger position, there is a sudden reduction in the size of elements located just underneath the outrigger.

It is worth noting that the proposed method considers only lateral load effects. If one takes vertical loads (such as gravity load) into account, the required sizes of the elements for bearing the vertical loads must be added to those obtained in this study. Although computer programs should be used in practice for final detailed analyses and design, the proposed method can be helpful in the early stage of design to provide an estimate of the member sizes as a reference for checking the computer results.

\section{References}

[1] I. Takewaki, Efficient semi-analytical generator of initial stiffness designs for steel frames under seismic loading. Part 1: Fundamental frame. Struct. Design Tall Build. 1997, 6(2), 151. DOI: 10.1002/(SICI)1099-1794(199706)6:2<151::AID-TAL90>3.0.CO;2-M.

[2] I. Takewaki, Efficient semi-analytical generator of initial stiffness designs for steel frames under seismic loading. Part 2: slender frame. Struct. Design Tall Build. 1997, 6(2), 163. DOI: 10.1002/(SICI)10991794(199803)7:1<91::AID-TAL90>3.0.CO;2-C. 
[3] P. Rahgozar, Free vibration of tall buildings using energy method and Hamilton's principle. Civil Eng. J. 2020, 6(5), 945. DOI: 10.28991/cej-2020-03091519.

[4] O.A. Bauchau, J.I. Craig, Euler-Bernoulli beam theory. In: Bauchau O.A., Craig J.I. (eds) Structural Analysis. Solid Mechanics and Its Applications, 163, 173-221. Springer, Dordrecht 2009. DOI: 10.1007/978-90-481-2516-6_5.

[5] B. S. Taranath, Structural Analysis and Design of Tall Buildings, McGraw-Hill, New York 1988.

[6] www.worldarchitecturemap.org/buildings/us-bank-center.

[7] R. Rahgozar, Y. Sharifi, An approximate analysis of combined system of framed tube, shear core and belt truss in high-rise buildings. Struct. Des. Tall Spec. Build. 2009, 18(6), 607. DOI: 10.1002/tal.503.

[8] Y. Chen, Z. Zhang, Analysis of outrigger numbers and locations in outrigger braced structures using a multiobjective genetic algorithm. Struct. Des. Tall Spec. Build. 2017, 27(1), e1408. DOI: 10.1002/tal.1408.

[9] R. Kamgar, P. Rahgozar, Reducing static roof displacement and axial forces of columns in tall buildings based on obtaining the best locations for multi-rigid belt truss outrigger systems. Asian Journal of Civil Engineering 2019, 20, 759-768. DOI: 10.1007/s42107-019-00142-0.

[10] R. Kamgar, P. Rahgozar, Optimum location for the belt truss system for minimum roof displacement of steel buildings subjected to critical excitation. Steel and Composite Structures 2020, 37(4), 463-479. DOI: $10.12989 / \mathrm{scs} .2020 .37 .4 .463$.

[11] S. Lee, A. Tovar, Outrigger placement in tall buildings using topology optimization. Eng. Struct. 2014, 74,122. DOI: 10.1016/j.engstruct.2014.05.019.

[12] Y. Chen, K. Cail, X. Wang, Parameter study of framed-tube structures with outriggers using genetic algorithm. Struct. Des. Tall Spec. Build. 2018, 27(14), e1499. DOI: 10.1002/tal.1499.

[13] Y. Zhou, C. Zhang, X. Lu, An inter-story drift-based parameter analysis of the optimal location of outriggers in tall buildings. Struct. Des. Tall Spec. Build. 2016, 25(5), 215. DOI: 10.1002/tal.1236.

[14] H.S. Kim, Optimum design of outriggers in a tall building by alternating nonlinear programming. Eng. Struct. 2017, 150, 91. DOI: 10.1016/j.engstruct.2017.07.043.

[15] H. S. Park, E. Lee, S.W. Choi, B.K. Oh, T. Cho, Y. Kim, Genetic-algorithm-based minimum weight design of an outrigger system for high-rise buildings. Eng. Struct. 2016, 117, 496. DOI: 10.1016/j.engstruct.2016.02.027.

[16] R. J. Balling, J.S. Lee, Simplified model for analysis and optimization of skyscrapers with outrigger and belt trusses. J. Struct. Eng. 2014, 141(9). DOI: 10.1061/(ASCE)ST.1943-541X.0001210.

[17] P. W. Christensen, A. Klarbring, An Introduction to Structural Optimization, Springer Science, Business Media BV 2009.

[18] A. Alavi, R. Rahgozar, P. Torkzadeh, Stiffness-based approach for preliminary design of framed tube structures. International Journal of Engineering. 2017, 30(11), 1664-1672. DOI: 10.5829/ije.2017.30.11b.06.

[19] A. Alavi, P. Rahgozar, R. Rahgozar, Minimum-weight design of high-rise structures subjected to flexural vibration at a desired natural frequency. Struct. Des. Tall Spec. Build. 2018, 27(15), e1515. DOI: 10.1002/tal.1515. 
[20] A. Alavi, R. Rahgozar, A simple mathematical method for optimal preliminary design of tall buildings with peak lateral deflection constraint. International Journal of Civil Engineering 2018, 17(7), 999. DOI: 10.1007/s40999-018-0349-1.

[21] A. Alavi, R. Rahgozar, Optimal stiffness distribution in preliminary design of tubed-system tall buildings. Struct. Eng. Mech. 2018, 65(6), 731. DOI: 10.12989/sem.2018.65.6.731.

[22] I.Takewaki, Optimal frequency design of tower structures via an approximation concept. Comput. Struct. 1996, 58(3), 445. DOI: 10.1016/0045-7949(95)00173-E.

[23] J. J. Connor, S. Laflamme, Structural Motion Engineering, Springer International Publishing, Switzerland 2014.

[24] K. S. Moon, J. J. Connor, J. E. Fernandez, Diagrid structural systems for tall buildings: characteristics and methodology for preliminary design. Struct. Des. Tall Spec. Build. 2007, 16(2), 205. DOI: 10.1002/tal.311.

[25] R. Karami Mohammadi, M. H. El Naggar, H. Moghaddam, Optimum strength distribution for seismic resistant shear buildings. International Journal of Solids and Structures 2004, 41(22-23), 6597. DOI: 10.1016/j.ijsolstr.2004.05.012.

[26] I. Hajirasouliha, H. Moghaddam, New lateral force distribution for seismic design of structures. $J$. Struct. Eng. 2009, 135(8). DOI: 10.1061/(ASCE)0733-9445(2009)135:8(906).

[27] H. Moghaddam, I. Hajirasouliha, Optimum strength distribution for seismic design of tall buildings. Struct. Des. Tall Spec. Build. 2008, 17(2), 331-349. DOI: 10.1002/tal.356.

[28] I. Hajirasouliha, K. Pilakoutas, General seismic load distribution for optimum performance-based design of shear-buildings. Journal of Earthquake Engineering. 2012, 16(4), 443-462. DOI: 10.1080/13632469.2012.654897.

[29] N. Nabid, I. Hajirasouliha, M. Petkovski, Adaptive low computational cost optimisation method for performance-based seismic design of friction dampers. Eng. Struct. 2019, 198. DOI: 10.1016/j.engstruct.2019.109549.

[30] J. M. Gere, S. P. Timoshenko, Mechanics of Materials, PWS Publishing Company 1990.

[31] Y. Chen, D. M. McFarland, Z. Wang, B. F. Spencer, L. A. Bergman, Analysis of tall buildings with damped outriggers. J. Struct. Eng. 2010, 136(11). DOI: 10.1061/(ASCE)ST.1943-541X.0000247.

[32] R. Kamgar, R. Rahgozar, A simple approximate method for free vibration analysis of framed tube structures. Struct. Des. Tall Spec. Build. 2010, 22(2), 217. DOI: 10.1002/tal.680.

[33] M. Malekinejad, R. Rahgozar, An analytical approach to free vibration analysis of multi-outriggerbelt truss-reinforced tall buildings. Struct. Des. Tall Spec. Build. 2011, 22(4), 382. DOI: 10.1002/tal.703.

[34] M. P. Bendsøe, O. Sigmund, Topology Optimization: Theory, Methods and Applications, Springer, Berlin Heidelberg, New York 2003.

[35] A. Alavi, M. Dolatabadi, J. Mashhadi, E. Noroozinejad Farsangi, Simultaneous optimization approach for combined control-structural design versus the conventional sequential optimization method. Struct. Multidiscip. Optim. 2020. DOI: 10.1007/s00158-020-02765-3. 
[36] R. Kamgar, R. Rahgozar, Determination of optimum location for flexible outrigger systems in tall buildings with constant cross section consisting of framed tube, shear core, belt truss and outrigger system using energy method. Int. J. Steel Struct. 2017, 17(1), 1-8. DOI: 10.1007/s13296-014-0172-8.

[37] S. Costanzo, M. D'Aniello, R. Landolfo, Seismic design criteria for chevron CBFs: Proposals for the next EC8 (part-2). Journal of Constructional Steel Research 2017, 138, 17-37. DOI: 10.1016/j.jcsr.2017.06.028.

[38] MATLAB R2015b, The MathWorks Inc., Natick, Massachusetts, United States 2015.

[39] A. Kwan, Simple method for approximate analysis of framed tube structures. J. Struct. Eng. 1994, 120(4), 1221. DOI: 10.1061/(ASCE)0733-9445(1994)120:4(1221).

[40] A. Alavi, F. Aloschi, D. Faiella, E. Mele, A simplified method for the preliminary design of coreoutrigger structures. XXVII Congress of the College of Technicians of Steel, 3-5 October, 2019, the University of Bologna, Italy.

[41] I. Hajirasouliha, P. Asadi, K. Pilakoutas, An efficient performance-based seismic design method for reinforced concrete frames. Earthquake Engineering and Structural Dynamics. 2012, 41(4), 663-679. DOI: 10.1002/eqe.1150.

[42] ETABS, Nonlinear Version 13.2.1, Computer and structures Inc., Berkeley, U.S.A. 2013. 